\title{
Familial Risk for Mood Disorder and the Personality Risk Factor, Neuroticism, Interact in Their Association with Frontolimbic Serotonin 2A Receptor Binding
}

\author{
Vibe G Frokjaer*,', Maj Vinberg², David Erritzoe', William Baaré ${ }^{1,3}$, Klaus Kähler Holst4, \\ Erik Lykke Mortensen ${ }^{5}$, Haroon Arfan', Jacob Madsen ${ }^{6}$, Terry L Jernigan ${ }^{1,3,7}$, Lars Vedel Kessing ${ }^{2}$ and \\ Gitte Moos Knudsen'
}

'Neurobiology Research Unit and Center for Integrated Molecular Brain Imaging, Denmark; '2Department of Psychiatry, Copenhagen University Hospital, Rigshospitalet, Denmark; ${ }^{3}$ Danish Research Centre for Magnetic Resonance, Hvidovre University Hospital, Denmark; ${ }^{4}$ Department of Biostatistics, University of Copenhagen, Denmark; ${ }^{5}$ Institute of Public Health, University of Copenhagen, Denmark; ${ }^{6}$ PET and Cyclotron Unit, Copenhagen University Hospital, Rigshospitalet, Denmark; ${ }^{7}$ Department of Psychiatry, University of California, Laboratory of Cognitive Imaging, San Diego, CA, USA

\begin{abstract}
Life stress is a robust risk factor for later development of mood disorders, particularly for individuals at familial risk. Likewise, scoring high on the personality trait neuroticism is associated with an increased risk for mood disorders. Neuroticism partly reflects stress vulnerability and is positively correlated to frontolimbic serotonin $2 \mathrm{~A}\left(5-\mathrm{HT}_{2 \mathrm{~A}}\right)$ receptor binding. Here, we investigate whether neuroticism interacts with familial risk in relation to frontolimbic $5-\mathrm{HT}_{2 \mathrm{~A}}$ receptor binding. Twenty-one healthy twins with a co-twin history of mood disorder and 16 healthy twins without a co-twin history of mood disorder were included. They answered self-report personality questionnaires and underwent $\left[{ }^{18} \mathrm{~F}\right]$ altanserin positron emission tomography. We found a significant interaction between neuroticism and familial risk in predicting the frontolimbic $5-\mathrm{HT}_{2 \mathrm{~A}}$ receptor binding $(p=0.026)$ in an analysis adjusting for age and body mass index. Within the high-risk group only, neuroticism and frontolimbic $5-\mathrm{HT}_{2 \mathrm{~A}}$ receptor binding was positively associated $(p=0.0037)$. In conclusion, our data indicate that familial risk and neuroticism interact in their relation to frontolimbic $5-\mathrm{HT}_{2 \mathrm{~A}}$ receptor binding. These findings point at a plausible neurobiological link between genetic and personality risk factors and vulnerability to developing mood disorders. It contributes to our understanding of why some people at high risk develop mood disorders while others do not. We speculate that an increased stress reactivity in individuals at high familial risk for mood disorders might enhance the effect of neuroticism in shaping the impact of potential environmental stress and thereby influence serotonergic neurotransmission.

Neuropsychopharmacology (20 I0) 35, I I29-I I37; doi:I 0.1038/npp.2009.2 I8; published online 30 December 2009
\end{abstract}

Keywords: 5-HT2A; depression; personality; neuroticism; stress; PET

\section{INTRODUCTION}

Stress is a robust risk factor for later development of mood disorders, particularly for individuals at familial risk. Seminal studies by Kendler et al, 1995 have shown interactions between familial risk and severe life stress in the risk of developing major depression. The background for a heritable stress vulnerability is most likely to be genetically complex in nature (Levinson, 2006), even though Caspi et al, 2003 have shown a link between stress vulnerability and the low expressing variant of a poly-

\footnotetext{
*Correspondence: Dr VG Frokjaer, Neurobiology Research Unit 9201, Copenhagen University Hospital, Rigshospitalet, Blegdamsvej 9, Copenhagen DK-2100, Denmark, Tel: + 453545 6712, Fax: + 45 356 7।3, E-mail: vibe@nru.dk

Received 5 July 2009; revised 16 November 2009; accepted 19 November 2009
}

morphism in the promoter region of the serotonin transporter gene, a finding that has been replicated in 15 independent studies so far (Uher and McGuffin, 2008). In a study by our group, we have, again, linked stress vulnerability and serotonergic neurotransmission by showing a coupling between the personality trait neuroticism and frontolimbic serotonin $2 \mathrm{~A}\left(5-\mathrm{HT}_{2 \mathrm{~A}}\right)$ receptor binding in a large sample of healthy volunteers (Frokjaer et al, 2008). Repeatedly, studies have shown that environmental experience moderates genes' effect on mental health. As such, identifying genetic vulnerability factors depends on focusing on relevant interactions with additional factors, for example environmental factors, that promote penetration of the genetic effects (Moffitt et al, 2005). One such additional factor to be taken into consideration is personality or general emotional response tendencies of an individual. The personality trait, neuroticism, reflects an individuals' 
tendency to experience negative emotions and ability to cope with stress, factors that are critical in the development of depression. The level of neuroticism will shape a persons' perception of potential environmental stress and hence modulate the impact of a stressful environment (Jacobs et al, 2006). It is well documented that neuroticism is a risk factor for developing depression (Fanous et al, 2007; Kendler et al, 1993a). The genetic factors influencing the development of the personality trait neuroticism only moderately overlap with genetic risk for developing major depression. In a large twin population of 20692 members of same-sex twin pairs, the genetic correlation between neuroticism and depression was estimated to be +0.46 (Kendler et al, 2006b); this correlation does not seem to be gender specific (Fanous et al, 2002). As such, a substantial proportion of the genetic vulnerability to major depression is not reflected in neuroticism and, therefore, may independently modulate the risk for mood disorders, and possibly also relate to serotonergic neurotransmission.

Serotonergic neurotransmission is an important component of the pathophysiology of mood disorders and, moreover, neuroticism is linked to serotonergic neurotransmission independent on familial risk for mood disorders or psychopathology (Frokjaer et al, 2008). Moreover, serotonergic neurotransmission is critical in the mechanisms of action of antidepressants. Although the major focus has been on the serotonin transporter, also $5-\mathrm{HT}_{2 \mathrm{~A}}$ receptor inhibition and down-regulation, for example as seen with SSRIs, mediate antidepressant treatment effects (14). Additional evidence for $5-\mathrm{HT}_{2 \mathrm{~A}}$ receptor changes in depression comes from post-mortem studies in the subset of depressed patients that commit suicide of which the majority report that $5-\mathrm{HT}_{2 \mathrm{~A}}$ receptor binding is increased in dorsolateral prefrontal cortex (Stockmeier, 2003). Although initial findings of in vivo receptor imaging studies were contradictory, two recent studies have confirmed that frontal cortex $5-\mathrm{HT}_{2 \mathrm{~A}}$ receptor binding is increased, both in recovered, un-medicated patients with a history of major depression (Bhagwagar et $\mathrm{al}, 2006$ ), and in un-medicated patients with severe depression (Meyer et al, 2003). Interestingly, negativistic thinking and $5-\mathrm{HT}_{2 \mathrm{~A}}$ receptor binding is correlated both in depressed patients (Bhagwagar et al, 2006; Meyer et al, 2003) and in healthy individuals (Frokjaer et al, 2008) in terms of dysfunctional attitudes and neuroticism scores, respectively. So far, no studies have investigated whether this coupling is a trait or state feature of depression. Here, we test whether the coupling between neuroticism and frontolimbic $5-\mathrm{HT}_{2 \mathrm{~A}}$ receptor binding is stronger in individuals at high familial risk as compared with individuals at low risk.

\section{MATERIALS AND METHODS}

Twenty-three healthy high-risk twins with a co-twin diagnosed with mood disorder and 18 low-risk twins whose co-twin did not have the diagnosis were initially included. They received brain magnetic resonance imaging (MRI) and $\left[{ }^{18} \mathrm{~F}\right]$ altanserin positron emission tomography (PET), were administered personality assessments, and were screened for psychiatric symptoms. Four subjects were excluded from analyses. In two cases, the measurement of plasma parent compound of $\left[{ }^{18} \mathrm{~F}\right]$ altanserin failed, and in one case, the radiochemistry production was too small. Finally, one low-risk participant was excluded as he was diagnosed with possible Tourette's syndrome post-inclusion. His twin brother and his nephew had severe Tourette's syndrome and this predisposition had not been noted in the initial psychiatric screening. Thus, 37 participants were available for analyses: 21 high risk (12 dizygotic (DZ), 9 monozygotic (MZ)) twins, with familial predisposition through unipolar (17) and bipolar (4) co-twins, mean age 39.3 years (22.1 to 60.9$)$, and 16 low-risk twins (10 DZ, 6 $\mathrm{MZ}$ ), mean age 38.6 (25.1 to 61.6) years. Female: male ratio was $13: 8$ (high risk) and 12:4 (low risk) reflecting the usual gender distribution in depression. The high-risk individuals' co-twin received their diagnosis at a mean age of $32 \pm 8.8$ years. All participants were lifetime naive for antidepressants and antipsychotics. Five women used hormonal contraception ( 2 high and 3 low risk). One used non-sedative antihistamine.

Healthy high-risk and low-risk individuals were identified by linking information from the Danish Twin Registry, the Danish Psychiatric Central Research Register, and the Danish Civil Registration System. This linkage identified same-sex twin pairs in which one twin had been treated in a psychiatric hospital setting for an affective episode and discharged with a diagnosis of depression or recurrent depression or a first diagnosis of manic mixed episode or bipolar affective disorder (from 1968 to 1993: ICD-8-codes 296.09, 296.29, 296.89, 296.99 and 296.19, 296.39, and from 1994: ICD-10-codes: F32-33.9 and F30-31.6, F34.0 F38.00) and the other twin had not (yet) been diagnosed with an affective disorder, the high-risk healthy co-twin. Low-risk twins were recruited from twin pairs in which both twins did not have a registered diagnosis or personal history of affective disorder. All subjects gave written informed consent.

The participants were part of a larger cohort enrolled in a high-risk study (Christensen et al, 2007; Vinberg et al, 2007). Of the total cohort of 234 individuals, 100 were below 60 years of age and able to undergo a magnetic resonance (MR) scan. Of these 100 eligible individuals, $45 \%$ from the high-risk group and $37 \%$ of the low-risk group participated, which did not represent a significant difference $(p=0.42$, Fischer's exact test).

Twelve of the participants from the low-risk group were also included in a study linking neuroticism and frontolimbic $5-\mathrm{HT}_{2 \mathrm{~A}}$ in 83 healthy volunteers (Frokjaer et al, 2008).

\section{Clinical Data, Symptom Scores, and Personality Assessment}

Participants were rated in a face-to-face interview by a trained clinician (MV). Persons with a lifetime diagnosis of mood disorder, schizoaffective disorder, or schizophrenia according to Schedules for Clinical Assessment in Neuropsychiatry (SCAN version 2.1) were excluded from the study. The Hamilton Depression Scale (HAM-D 17-item) was used to assess depressive symptoms. Self-rating of psychopathology was assessed with the 21-item Beck Depression Inventory (BDI 21), and the 14-item Anxiety Subscale (BDI 14) as described elsewhere (Christensen et al, 2007). 
Participants were interviewed about stressful life events (SLE) in the year before inclusion (recent life events), as described elsewhere (Vinberg et al, 2007).

Participants also completed the Danish version of the 240 item NEO-PI-R (NEO Personality Inventory Revised) selfreport personality questionnaire (Skovdahl-Hansen et al, 2004) on the same day as the PET scanning. NEO-PI-R evaluates the broad personality dimensions of neuroticism, extraversion, openness, agreeableness, and conscientiousness. Each dimension score is derived by adding the scores from assessment of six constituent personality traits (facets), and each trait score is derived by adding the scores on eight items. The overall neuroticism score was the outcome measure. Post hoc, the contribution from the constituent traits of neuroticism (anxiety, depression, selfconscientiousness, vulnerability, impulsiveness, and angry hostility) was evaluated.

\section{Imaging}

The $5-\mathrm{HT}_{2 \mathrm{~A}}$ receptor binding was imaged with $\left[{ }^{18} \mathrm{~F}\right]$ altanserin PET according to Pinborg et al (2003) using a maximum dose of $3.7 \mathrm{MBq} / \mathrm{kg}$ bodyweight. After bolus infusion of tracer for $2 \mathrm{~h}$ to attain tracer steady state conditions, $40 \mathrm{~min}$ emission scans were acquired as a sequence of five frames of each $8 \mathrm{~min}$, with an 18-ring GEAdvance scanner (GE, Milwaukee, Wisconsin) operating in $3 \mathrm{D}$-acquisition mode. The total axial field of view was $15.2 \mathrm{~cm}$ with an approximate in-plane resolution of $6 \mathrm{~mm}$. During scanning, the fraction of un-metabolized tracer in venous plasma was determined at three time points using high performance liquid chromatography analysis. Reconstruction, including attenuation correction, and scatter correction are described in detail elsewhere (Pinborg et al, 2003). The five frames of PET data were aligned using the AIR algorithm (Woods et al, 1992). Structural MR brain imaging was conducted in all subjects; MPRAGE sequences were acquired on a $3 \mathrm{~T}$ scanner (Trio, Siemens, Erlangen, Germany).

\section{MR/PET Co-registration}

PET and MR images were co-registered through manual translation and rotation of the PET image with subsequent visual inspection in three planes, as described in Adams et al (2004). Data analyses were carried out by the same person.

\section{Volumes of Interest and Partial-Volume Correction}

On the basis of the method by Svarer et al (2005), a frontolimbic volume was automatically delineated on each individual's transaxial MRI slices in a strictly userindependent manner. This method uses a volumes of interest (VOI) probability map based on a template set of 10 MRIs, in which VOIs have been defined manually. The frontolimbic volume was the volume of interest based on our earlier findings of a coupling between neuroticism and frontolimbic $5-\mathrm{HT}_{2 \mathrm{~A}}$ receptor binding in a large sample of healthy volunteers (Frokjaer et al, 2008). The frontolimbic volume included orbitofrontal, medial inferior frontal, superior frontal, anterior cingulate, posterior cingulate, hippocampus, and entorhinal cortices.

To enable partial-volume correction of the PET data, MRIs were segmented into gray matter, white matter, and cerebrospinal fluid tissue classes using Statistical Parametric Mapping (SPM2; Wellcome Department of Cognitive Neurology, London, UK). Partial-volume correction was performed according to Müller-Gärtner et al (1992), as defined in Quarantelli et al (2004).

\section{Quantification of the 5- $\mathrm{HT}_{2 \mathrm{~A}}$ Receptor Binding}

The outcome parameter was the binding potential of specific tracer binding $\left(\mathrm{BP}_{\mathrm{P}}\right)$. Cerebellum was used as a reference region as it represents non-specific binding only (Pinborg et al, 2003). $\mathrm{BP}_{\mathrm{P}}$ is defined as follows:

$$
\mathrm{BP}_{\mathrm{P}}=\left(C_{\mathrm{VOI}}-C_{\text {Reference }}\right) / C_{\text {Plasma }}=f_{\mathrm{p}} *\left(B_{\max } / K_{\mathrm{d}}\right)(\mathrm{ml} / \mathrm{ml})
$$

where $C_{\text {VOI }}$ and $C_{\text {Reference }}$ are mean counts in steady state in the VOI and in the reference region, respectively, $C_{\text {Plasma }}$ is the steady state activity of non-metabolized tracer in plasma, $f_{\mathrm{P}}$ is the free fraction of radiotracer, $B_{\max }$ is the density of receptor sites available for tracer binding, and $K_{\mathrm{d}}$ is the affinity constant of the radiotracer to the receptor (Pinborg et al, 2003). The non-specific binding was calculated as the partial-volume corrected gray-matter cerebellar regional concentration (counts/(s ml)) normalized by the plasma concentration, $C_{\text {Plasma, }}$ (counts/(s ml)).

$\left[{ }^{18} \mathrm{~F}\right]$ altanserin gives rise to a radiolabelled metabolite that crosses the blood brain barrier; however, with the bolusinfusion study design, the non-specific binding is subtracted and thus the $\mathrm{BP}_{\mathrm{P}}$ is independent of the metabolite fraction.

\section{Statistics}

Group comparisons of clinical data were performed using unpaired $t$-tests. Differences in proportions were tested with Fischer's exact test. Uncorrected $p$-values are reported.

Main effects of neuroticism, risk, gender, smoking, symptom scores, and SLE on frontolimbic $5-\mathrm{HT}_{2 \mathrm{~A}}$ receptor binding were tested by multiple linear regression analysis in a model adjusting for age and body mass index (BMI), known to be associated with $5-\mathrm{HT}_{2 \mathrm{~A}}$ receptor binding (Erritzoe et al, 2009).

To explore whether the association between frontolimbic $5-\mathrm{HT}_{2 \mathrm{~A}}$ receptor binding and neuroticism was strongest in the group at high familial risk, we tested the interaction between neuroticism and risk in a multiple linear regression analysis with frontolimbic $5-\mathrm{HT}_{2 \mathrm{~A}}$ receptor binding as the outcome parameter and age, BMI, neuroticism, risk status, and 'neuroticism by risk' as covariates.

The effect of 'zygosity by risk' was also tested assuming that a genetic effect would be most prominent in MZ highrisk subjects followed by DZ high-risk and the low-risk subjects. Post hoc, the effect of 'gender by risk' interaction was tested, as some genetic-risk factors are likely to be sex specific in their effect (Kendler et al, 2006a).

Linearity of quantitative variables was confirmed by including second order terms in the models. Variance homogeneity and normality were assured by graphical evaluation. Model assumptions were met. 
The $p$-values, as estimated by two sided tests, parameter estimates with standard errors and 95\% confidence limits, and degrees of freedom (DF) are reported when appropriate. The $p$-values $<0.05$ were considered statistically significant. The analyses were performed in R 2.5.1 (http:// www.R-project.org).

\section{RESULTS}

\section{Group Differences and Main Effects}

Demographical data and symptom scores for high- and lowrisk individuals are given in Table 1 . The only statistically significant difference between the total high- and low-risk groups was that the high-risk group smoked more $(p=0.035)$. At the subgroup level, the low-risk group differed from the high-risk DZ group in proportion of smokers $(p=0.038)$ and in cigarettes per day $(p=0.008)$ only. Imaging outcomes are reported in Table 2 . There were no significant group differences in frontolimbic $\mathrm{BP}_{\mathrm{P}}$, nonspecific binding, $C_{\text {Plasma }}$ or $f_{\mathrm{p}}$ even at the uncorrected level.

Neuroticism tended to correlate with frontolimbic $5-\mathrm{HT}_{2 \mathrm{~A}}$ receptor binding in a simple model adjusting for age and BMI only (slope: 0.010 , confidence limits: [ $-0.00013 ; 0.021]$ $\mathrm{BP}_{\mathrm{P}}$ per neuroticism unit, $\left.p=0.053\right)$. In this model, age had a significant negative (slope: -0.017 , confidence limits: $[-0.033 ;-0.0016] \mathrm{BP}_{\mathrm{P}}$ per year, $\left.p=0.032\right)$, and $\mathrm{BMI}$ a positive (slope: 0.090 , confidence limits: [0.025; 0.15] $\mathrm{BP}_{\mathrm{P}}$ per BMI unit, $p=0.0080$ ) effect on binding as expected (Erritzoe et al, 2009). We saw no main effects of familial risk, gender, smoking, symptom scores, or SLE on frontolimbic $5-\mathrm{HT}_{2 \mathrm{~A}}$ receptor binding when adjusting for age and BMI (Table 2). Further, we observed no effects of bi- $v s$ unipolar co-twin history, years passed from age of onset/diagnosis of co-twin, or age of onset/diagnosis of the co-twin (Table 2).

\section{Effect of Familial Risk on the Association Between Frontolimbic 5- $\mathrm{HT}_{2 \mathrm{~A}}$ Receptor Binding and Neuroticism}

As illustrated in Figure 1, we saw an interaction between neuroticism and risk in the expected direction, that is the association between neuroticism and frontolimbic $5-\mathrm{HT}_{2 \mathrm{~A}}$ receptor binding was stronger in the high-risk group (difference in slopes: 0.023 , confidence limits: [0.0030; $0.043]_{\mathrm{BP}_{\mathrm{P}}}$ per neuroticism unit, $p=0.026$, DF: 31$)$. Within the high-risk group, neuroticism and frontolimbic $5-\mathrm{HT}_{2 \mathrm{~A}}$ receptor binding was positively associated (slope: 0.027, confidence limits: [0.0093; 0.044] $\mathrm{BP}_{\mathrm{P}}$ per neuroticism unit, $p=0.0037)$, whereas this association was not significant in the low-risk group (slope: 0.0037, confidence limits: $[-0.0080 ; 0.015] \mathrm{BP}_{\mathrm{P}}$ per neuroticism unit, $p=0.52$, DF: 31 ).

When adding zygosity to the model, the two high-risk groups of increasing risk load (high-risk DZ $<$ high-risk MZ) showed the expected hierarchy in terms of increasing association between frontolimbic $5-\mathrm{HT}_{2 \mathrm{~A}}$ and neuroticism (high-risk DZ: slope: 0.019, confidence limits: [ -0.005 ; 0.042 ] $\mathrm{BP}_{\mathrm{P}}$ per neuroticism unit, $p=0.12$, and high-risk $\mathrm{MZ}$ : slope: 0.028 , confidence limits [0.0007; 0.056] $\mathrm{BP}_{\mathrm{P}}$ per neuroticism unit, $p=0.045$, DF: 28). This hierarchy represented a trend only, $p=0.12$. For comparison, the slope estimate for the low-risk group was closer to zero, Figure 2.

Table I Comparison of Clinical Data

Total groups

\begin{tabular}{lcc}
\hline High-risk & Low-risk & p-value \\
$N=21$ & $N=16$ &
\end{tabular}

Age (years)

Gender (\% women)

Smoking (\% smokers)

Cigarettes per day

Alcohol (units/week)

Body mass index

Education years

Hamilton

$\mathrm{BDI}$ depression

BDI anxiety

Neuroticism

SLE, three or more

Twin age of onset

Years without diagnosis

$39.3 \pm 11.9$
$62 \%$
$48 \%$
$6.9 \pm 8.0$
$7.1 \pm 8.0$
$23.9 \pm 3.1$
$12.7 \pm 2.8$
$2.7 \pm 1.3$
$2.2 \pm 2.5$
$0.9 \pm 1.4$
$71 \pm 14$
$40 \%$
$32.2 \pm 8.8$
$7.0 \pm 7.6$

Sub-groups

\begin{tabular}{cc}
\hline $\begin{array}{c}\text { High-risk MZ } \\
\mathbf{N}=\mathbf{9}\end{array}$ & $\begin{array}{c}\text { High-risk } \mathbf{~ D Z} \\
\mathbf{N}=\mathbf{I} \mathbf{2}\end{array}$ \\
\hline $41.3 \pm 12.1$ & $38.0 \pm 12.1$ \\
$78 \%$ & $50 \%$ \\
$33 \%$ & $58 \%$ \\
$4.4 \pm 6.8$ & $8.8 \pm 8.6$ \\
$5.6 \pm 5.9$ & $8.3 \pm 9.5$ \\
$24.4 \pm 3.2$ & $23.4 \pm 3.0$ \\
$12.9 \pm 2.2$ & $12.6 \pm 3.3$ \\
$2.3 \pm 1.0$ & $3.0 \pm 1.5$ \\
$1.7 \pm 1.7$ & $2.7 \pm 2.9$ \\
$0.67 \pm 1.0$ & $1.1 \pm 1.7$ \\
$76 \pm 13$ & $68 \pm 14$ \\
$44 \%$ & $33 \%$ \\
$33.3 \pm 8.0$ & $31.6 \pm 9.6$ \\
$7.7 \pm 10.3$ & $6.4 \pm 5.2$ \\
\hline
\end{tabular}

BDI depression: Becks Depression Inventory, depression symptoms component (2I items); BDI anxiety: anxiety component (I4 items); Hamilton: Hamilton Depression rating Scale score of depressive symptoms ( 17 items); SLE: the fraction of participants experiencing three or more stress-full life events within the last 12 months; neuroticism: score from 240-item NEO-PI-R, Danish version; body mass index: weight/height ${ }^{2}\left(\mathrm{~kg} / \mathrm{m}^{2}\right)$; smoking: proportion of smokers; years without diagnosis: number of years passed from age of onset of mood disorder of co-twin and the PET-scan; MZ: monozygotic; DZ: dizygotic; NA: not applicable; statistics: for the total high-risk and low-risk groups differences in numerical variables were tested by unpaired $t$-tests, differences in proportions by Fischer's exact test; $p$-values are reported with no corrections for multiple comparisons. Data for the high-risk subgroups are included for descriptive purposes. 
Table 2 Comparison of Imaging Outcome Parameters

\begin{tabular}{|c|c|c|c|c|c|}
\hline & \multicolumn{3}{|c|}{ Total groups } & \multicolumn{2}{|c|}{ Sub-groups } \\
\hline & $\begin{array}{l}\text { High-risk } \\
N=21\end{array}$ & $\begin{array}{c}\text { Low-risk } \\
N=16\end{array}$ & $p$-value & $\begin{array}{c}\text { High-risk MZ, } \\
\qquad \mathbf{N}=\mathbf{9}\end{array}$ & $\begin{array}{c}\text { High-risk DZ, } \\
\quad N=12\end{array}$ \\
\hline Frontolimbic $\mathrm{BP}_{\mathrm{P}}$ (unitless) & $2.56 \pm 0.64$ & $2.76 \pm 0.48$ & 0.32 & $2.86 \pm 0.61$ & $2.34 \pm 0.60$ \\
\hline Non-specific binding (unitless) & $1.97 \pm 0.53$ & $2.10 \pm 0.67$ & 0.52 & $2.16 \pm 0.65$ & $1.83 \pm 0.39$ \\
\hline$C_{\text {plasma }} \mathrm{kBq} / \mathrm{ml}$ & $1.92 \pm 0.51$ & $2.02 \pm 0.38$ & 0.50 & $1.88 \pm 0.52$ & $1.95 \pm 0.52$ \\
\hline
\end{tabular}

BP : binding potential of specific $\left[{ }^{18} \mathrm{~F}\right]$ altanserin binding; $C_{\text {plasma: }}$ steady state activity of non-metabolized $\left[{ }^{18} \mathrm{~F}\right]$ altanserin in plasma; $f_{p}$ : free (non-protein bound) fraction of $\left[{ }^{18} \mathrm{~F}\right]$ altanserin in plasma; MZ: monozygotic; DZ: dizygotic. Non-specific binding is the volume-weighted average partial volume corrected counts per second in the cerebellum gray-matter divided by $C_{\text {plasma; }}$ statistics: for the total high-risk and low-risk groups, differences in numerical variables were tested by unpaired $t$-tests. Data for the high-risk subgroups are included for descriptive purposes.

The association between neuroticism and $5-\mathrm{HT}_{2 \mathrm{~A}}$ receptor binding in the high-risk group was primarily driven by the constituent traits self-conscientiousness $(p=0.005)$, anxiety $(p=0.020)$, depression $(p=0.025)$, and less convincingly by vulnerability $(p=0.12)$, whereas little or no association was seen with impulsivity $(p=0.24)$ or angry hostility $(p=0.27)$, DF: 17 .

\section{Gender by Risk Interaction}

In high-risk females, the association between frontolimbic $5-\mathrm{HT}_{2 \mathrm{~A}}$ receptor binding and neuroticism was more pronounced than in the remaining group (difference in slope: $0.029 \mathrm{BP}_{\mathrm{P}}$ per neuroticism unit, confidence limits: [0.0061; 0.051], $p=0.014$, DF: 31$)$. Within the group of 13 high-risk females, the effect of neuroticism on frontolimbic $5-\mathrm{HT}_{2 \mathrm{~A}}$ receptor binding adjusted for age and BMI was $0.033 \mathrm{BP}_{\mathrm{P}}$ per neuroticism unit, confidence limits: [0.013; $0.054], p=0.0021$.

\section{DISCUSSION}

We have shown that the association between frontolimbic $5-\mathrm{HT}_{2 \mathrm{~A}}$ receptor binding and neuroticism, initially observed in healthy volunteers (Frokjaer et al, 2008), is stronger in individuals at high familial risk of developing mood disorders than in individuals at low risk. These results are consistent with the hypothesis that familial risk of developing mood disorders modifies the association between frontolimbic $5-\mathrm{HT}_{2 \mathrm{~A}}$ receptor binding and neuroticism. As the study design did not include both twins in a pair, a traditional analysis of the relative contribution from genetic $v s$ shared early environmental factors could not be undertaken, but this was not the aim of the study. We did, however, see that the high-risk groups of increasing risk load tended to show an increasing association between frontolimbic $5-\mathrm{HT}_{2 \mathrm{~A}}$ and neuroticism suggesting that genetic-risk factors have a function in modifying the association.

The interaction between neuroticism and familial risk in predicting frontolimbic $5-\mathrm{HT}_{2 \mathrm{~A}}$ receptor binding may be genetically based, and/or be related to disturbances in serotonin homeostasis, and to increased stress reactivity, which is possibly associated with both neuroticism (Portella

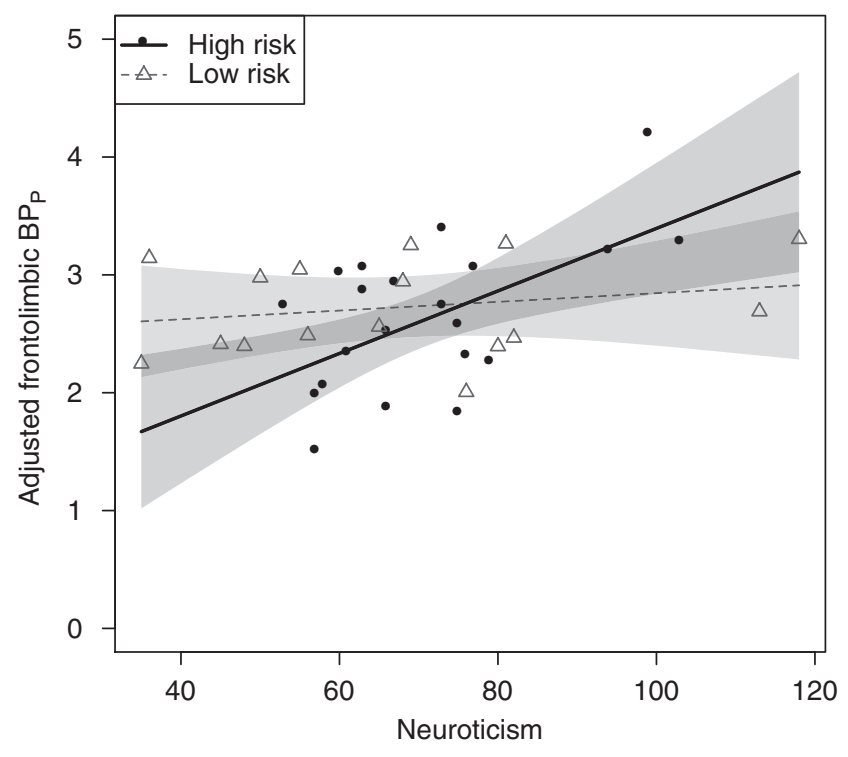

Figure I Effect of familial risk on the association between frontolimbic $5-\mathrm{HT}_{2 \mathrm{~A}}$ receptor $\mathrm{BP}_{\mathrm{P}}$ and neuroticism, adjusted for $\mathrm{BMI}$ and age. In the high end of the neuroticism scale, the high-risk group showed an elevated $\mathrm{BP}_{\mathrm{P}}$, whereas in the low end, they showed a decreased $\mathrm{BP}_{\mathrm{p}}$ as compared with the low-risk group. This reflects the stronger association between neuroticism and frontolimbic $5-\mathrm{HT}_{2 \mathrm{~A}}$ receptor binding in individuals at high familial risk of developing mood disorders $(p=0.026)$. The high-risk group showed a significant positive association between neuroticism and frontolimbic $5-\mathrm{HT}_{2 \mathrm{~A}}$ receptor binding, whereas the low-risk group did not. Please see text for estimates. Point-wise $95 \%$ symmetric confidence bands of the regression lines are displayed. The regression lines represent the associations given a mean BMI and mean age.

et al, 2005) and familial risk of developing mood disorder (Mannie et al, 2007; Modell et al, 1998). Such relations may be established in early brain development (Gaspar et al, 2003). Chronic disturbances in serotonin homeostasis may affect $5-\mathrm{HT}_{2 \mathrm{~A}}$ receptor levels; increased synaptic serotonin is suggested to lead to $5-\mathrm{HT}_{2 \mathrm{~A}}$ receptor down-regulation (Meyer et al, 2001; Gunther et al, 2008), whereas low synaptic serotonin may up-regulate $5-\mathrm{HT}_{2 \mathrm{~A}}$ receptor levels (Cahir et al, 2007; Heal et al, 1985). The latter could be linked to high risk of developing mood disorders. However, our data does not support that familial risk in itself is associated with increased frontolimbic $5-\mathrm{HT}_{2 \mathrm{~A}}$ receptor binding, as we observed no differences in binding between 


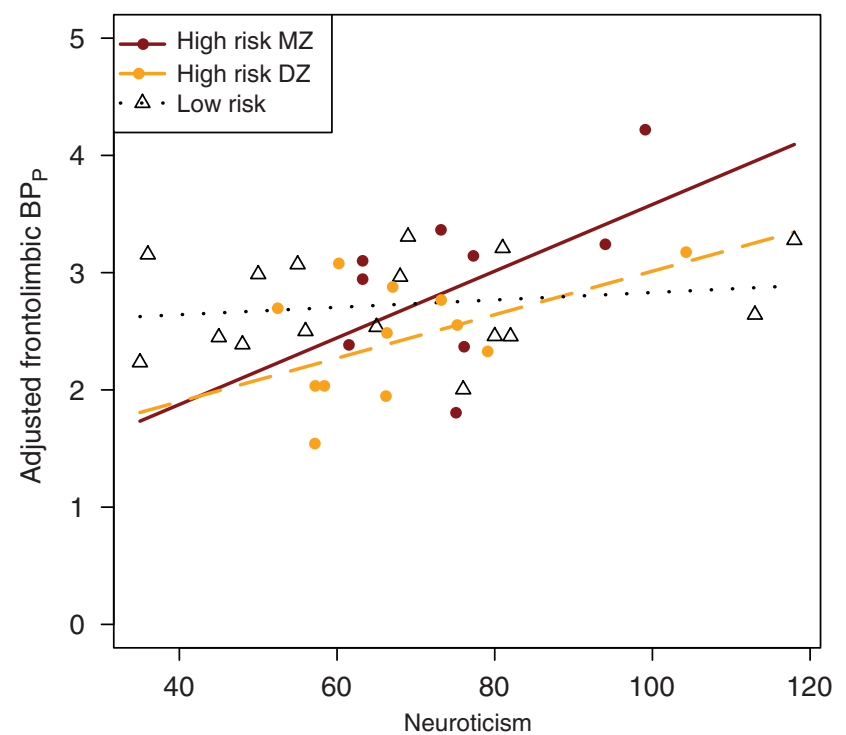

Figure 2 Effect of zygosity and familial risk on the association between frontolimbic $5-\mathrm{HT}_{2 \mathrm{~A}}$ receptor binding and neuroticism, adjusting for $\mathrm{BMI}$ and age. Genetic risk load: (low-risk $D Z$ and $M Z<$ high-risk $D Z<$ highrisk $M Z$ ). The high-risk $M Z$ group shows the strongest association followed by the high-risk DZ group and the low-risk group. However, the differences in slopes between groups represented a trend only $(p=0.12)$.

the low-risk and the high-risk groups. Moreover, there were no between group differences in non-specific binding, plasma concentration, or free fraction of tracer indicating that such differences have not driven the study results.

Stress responses may critically interfere with serotonergic neurotransmission, and increased stress responsiveness is associated with an increased risk of developing a mood disorder. Animal studies support that chronic stress is associated with up-regulation of frontal $5-\mathrm{HT}_{2 \mathrm{~A}}$ receptor binding particularly in vulnerable rat strains characterized by anxious (Berton et al, 1998) and depressive-like behaviors (Dwivedi et al, 2005). Moreover, in organotypic hippocampal cultures, chronic exposure ( 7 days) to corticosterone increased $5-\mathrm{HT}_{2 \mathrm{~A}}$ protein levels (Trajkovska et al, 2009). Furthermore, several studies suggest a link between increased biological stress reactivity and the serotonergic transmitter system in terms of the low expressing polymorphism of the serotonin transporter promoter gene (Barr et al, 2004b; Gotlib et al, 2008), a gene that is also associated with an increased vulnerability to develop depression in response to life stress (Uher and McGuffin, 2008). Apart from genetic factors, stress reactivity also varies with environmental factors including early life stress (Kajantie, 2006; Talge et al, 2007) and emotional response tendencies (Mormede et al, 2002), for example personality, in human beings (Portella et al, 2005). Therefore, interestingly, the stronger association between neuroticism and $5-\mathrm{HT}_{2 \mathrm{~A}}$ receptor binding in individuals at high familial risk of developing mood disorders may reflect an increased sensitivity to environmental stress in those individuals. As the level of neuroticism will shape a person's perception of potential stressful experiences and as such modify the impact of environmental stress (Jacobs et al, 2006), neuroticism and familial risk may interact in predicting $5-\mathrm{HT}_{2 \mathrm{~A}}$ receptor binding. However, the explanation of possible mechanisms remains speculative. Unfortunately, we have no measures of physiological stress reactivity, for example waking cortisol. Thus, we cannot validate that the high-risk group had enhanced stress reactivity.

Longitudinal studies with clinical follow-up of high-risk individuals will be needed to explore whether the combination of high neuroticism and high frontolimbic $5-\mathrm{HT}_{2 \mathrm{~A}}$ receptor binding would predict later development of mood disorder. However, the involvement of $5-\mathrm{HT}_{2 \mathrm{~A}}$ receptor binding in major depression has been explored in several cross-sectional postmortem (Stockmeier, 2003) and imaging studies (Attar-Levy et al, 1999; Biver et al, 1997; Yatham et al, 2000; Messa et al, 2003) of which two studies took into account measures of negativistic thinking. A recent study by Bhagwagar et al (2006), in un-medicated, euthymic patients recovered from depression, support that a higher frontolimbic $5-\mathrm{HT}_{2 \mathrm{~A}}$ receptor level may be a trait factor of the susceptibility to develop depression and correlate positively with measures of negativistic thinking. Moreover, Meyer et al, 2003 found that in currently depressed patients, cortical, predominantly frontal, 5- $\mathrm{HT}_{2}$ receptor binding was correlated to dysfunctional attitudes (pessimistic, negativistic thinking), whereas only the subgroup of patients with the most prominent negativistic thinking had a higher frontal $5-\mathrm{HT}_{2}$ receptor binding than healthy controls. As such, even in the depressed state, a positive association between negativistic thinking and frontal $5-\mathrm{HT}_{2 \mathrm{~A}}$ receptor binding seems to exist. In none of these studies, however, was neuroticism directly taken into account.

Neuroticism mean score and variance did not differ significantly between individuals at high $v s$ low risk and hence, the stronger association in the high-risk group is not driven by a larger variance in neuroticism score. This is in accordance with an analysis in a larger cohort of 211 healthy high-risk and low-risk individuals from the same study in which no difference in neuroticism score could be identified when correcting for gender, minor psychopathology, and the effect of SLE (Vinberg et al, 2007).

In this study, we also replicated the earlier observed association between neuroticism and frontolimbic 5- $\mathrm{HT}_{2 \mathrm{~A}}$ receptor binding (Frokjaer et al, 2008) this time, in an independent sample of 21 healthy individuals at high familial risk of developing mood disorders. As observed earlier, some constituent traits of neuroticism contribute more to the association. Whereas we did not see such a strong relationship with vulnerability, as earlier (Frokjaer et al, 2008), a subset of the neuroticism traits consisting of the facets self-consciousness, depression, anxiety, and vulnerability contributed to the association in subjects at high familial risk. Although these traits inherently reflect sensitivity to stress and trauma, the remaining two facets of neuroticism, angry hostility, and impulsiveness clearly reflect a disposition to more active reaction when faced with frustration (Skovdahl-Hansen et al, 2004). Interestingly, in this independent sample, we confirmed our earlier finding that angry hostility and impulsiveness facets of neuroticism do not contribute to the correlation between high frontolimbic $5-\mathrm{HT}_{2 \mathrm{~A}}$ receptor binding and neuroticism. Therefore, we speculate that angry hostility and impulsiveness may not significantly contribute to the personality 
Table 3 Main Effects of Clinical Variables on Frontolimbic 5- $\mathrm{HT}_{2 \mathrm{~A}}$ Receptor Binding in a Model Adjusting for Age and BMI

\begin{tabular}{lcclcc}
\hline Variable & Estimate & SE & $\begin{array}{c}\text { 95\% Confidence } \\
\text { limits }\end{array}$ & p-value & DF \\
\hline Gender & 0.13 & 0.20 & $(-0.26 ; 0.53)$ & 0.50 & 33 \\
Smoking & 0.036 & 0.20 & $(-0.37 ; 0.44)$ & 0.86 & 33 \\
Cigarettes per day & 0.0005 & 0.014 & $(-0.027 ; 0.09 I)$ & 0.97 & 33 \\
BDI_depression & 0.0035 & 0.048 & $(-0.095 ; 0.10)$ & 0.94 & 31 \\
BDI_anxiety & 0.017 & 0.069 & $(-0.12 ; 0.16)$ & 0.81 & 31 \\
Hamilton & -0.047 & 0.073 & $(-0.20 ; 0.10)$ & 0.52 & 32 \\
SLE-3 or more & -0.28 & 0.21 & $(-0.70 ; 0.14)$ & 0.18 & 31 \\
Neuroticism & 0.010 & 0.0052 & $(-0.00013 ; 0.021)$ & 0.053 & 33 \\
Risk-status & -0.014 & 0.19 & $(-0.53 ; 0.25)$ & 0.46 & 33 \\
Bi or unipolar & 0.0062 & 0.37 & $(-0.78 ; 0.79)$ & 0.99 & 17 \\
Age of onset & -0.0060 & 0.027 & $(-0.063 ; 0.051)$ & 0.83 & 17 \\
'Years passed' & 0.0060 & 0.027 & $(-0.051 ; 0.063)$ & 0.83 & 17 \\
\hline
\end{tabular}

Gender: women > men; smoking: smoker > non-smoker; SLE_3 or more: 3 or more > 0, I ,2 SLE; risk-status: high-risk > low-risk. The effects of diagnoses, age of onset, and 'years passed' concern the high-risk group only. Bi or unipolar diagnoses of co-twin: diagnosis at first admission; age of onset: age of first diagnosis; years passed: number of years passed since age of onset of mood disorder of co-twin to PET-scan; DF: degrees of freedom.

related risk of developing depressive disorder and that the subset of neuroticism is a more sensitive risk marker.

The frequency of current smokers was significantly higher in the high-risk group than in the low-risk group. This is well in line with the observation that people with current or past depression are more likely to have been smokers at some point in their lives, and may even reflect common genetic factors between smoking addiction and risk of developing depression (Kendler et al, 1993b). Smoking inhibits degradation of serotonin by inhibiting the monoamine-oxidase- $\mathrm{A}$ and may, therefore, potentially lead to decreased frontal $5-\mathrm{HT}_{2 \mathrm{~A}}$ receptor binding through adaptation to increased serotonin levels. However, such an effect was not observed in the present sample, Table 3, and has not been shown in a large sample of healthy volunteers (Erritzoe et al, 2009). Therefore, we do not expect that this have biased our findings. Nevertheless, if significant, smoking in the high-risk group would bias our results towards no interaction, opposite our findings.

Even though gender does not significantly influence the $5-\mathrm{HT}_{2 \mathrm{~A}}$ receptor binding, we observed a 'gender by risk' interaction suggesting a gender-related effect of familialrisk factors on the association between frontolimbic $5-\mathrm{HT}_{2 \mathrm{~A}}$ receptor binding and neuroticism. However, as this study was not designed to detect gender by risk interactions, this finding will need to be replicated in a more focused design. If sustained, this may reflect gender-specific differences in genetic vulnerability to environmental stress (Barr et al, 2004a; Brummett et al, 2007).

\section{Methodological Considerations}

Our results should be interpreted in the context of some potentially significant methodological considerations.
First, the high-risk group consisted of subjects with variable risk load and several aspects potentially contributed to reduce the risk as follows:

(a) A tendency towards a late age of onset of the affected co-twin - The average age of diagnosis of the co-twin was $32.2 \pm 8.8$ years, with three affected co-twins being older than 40 years $(43,47$, and 54$)$. The typical age of onset for bipolar disorder is 18 years (Pini et al, 2005), and for major depression, it is 30 years (Hasin et al, 2005).

(b) A large variation in the period of time between inclusion in our study and onset of the co-twin's mood disorder-The mean symptom-free interval was $7.0 \pm 7.6$ years, but for three subjects $>10$ years passed from the age of onset of the co-twin $(10,20$, and 34 years). These subjects, despite their predisposition, did not develop mood disorders for a long time and may, therefore, be protected.

(c) Subjects volunteering for an extensive investigation program, including a PET study, would possibly tend to be more vigorous. However, they are not expected to differ with regard to neuroticism score (Frokjaer et al, 2008).

Consequently, had the group been more selected towards high risk, it is possible that an even stronger association between frontolimbic $5-\mathrm{HT}_{2 \mathrm{~A}}$ receptor binding and neuroticism would have been present.

Second, high-risk subjects with unipolar and bipolar predisposition were pooled (17 unipolar and 4 bipolar). It is possible that unipolar and bipolar disorder constitute a continuous spectrum, rather than being categorically distinct (Akiskal and Benazzi, 2006). More importantly, keeping our main goal, to identify high-risk individuals, in mind, there is no difference in the frequency of unipolar depression in relatives of unipolars and bipolars (Kutcher and Marton, 1991).

Third, we studied twins and, thus, the outcome may not be representative of singletons. However, several studies support that both MZ and DZ twins resemble the background population in their risk for mood disorders (Kendler et al, 1996).

Finally, the post hoc analyses on effect of zygosity in the high-risk group and gender by risk effect on the association between neuroticism and frontolimbic $5-\mathrm{HT}_{2 \mathrm{~A}}$ receptor binding represent trends only. The generated hypotheses need to be confirmed in future studies.

In conclusion, our data suggest that familial risk of developing mood disorders modifies the positive association between frontolimbic $5-\mathrm{HT}_{2 \mathrm{~A}}$ receptor binding and neuroticism. The stronger association between neuroticism and frontolimbic $5-\mathrm{HT}_{2 \mathrm{~A}}$ receptor binding in individuals at high familial risk may reflect an increased stress reactivity that enhances the effect of neuroticism in shaping the impact of potential environmental stress and thereby influences serotonergic neurotransmission.

\section{ACKNOWLEDGEMENTS}

We are grateful to the participants. We thank Karin Stahr, Dorthe Givard, and the staff at the PET centre, 
Rigshospitalet for their superb technical assistance. Thanks to the Department of Psychiatric Demography, University of Aarhus, Psychiatric Hospital, Riskov, Denmark, and to the Danish Twin Registry for cooperation in the study. The John and Birthe Meyer Foundation is thanked for the donation of the Cyclotron and PET scanner. This work was generously supported by Danish Medical Research Council, The Health Science Faculty, University of Copenhagen, the 1991 Pharmacy Foundation, The Lundbeck Foundation, the EU Sixth framework programme (EC-FP6-project DiMI (LSHB-CT-2005-512146)), Sawmill owner Jeppe Juhl and Wife Ovita Juhls Foundation, 'Laegernes forsikringsforening af 1891,' and 'Fonden af 1870.'

\section{DISCLOSURE}

The authors declare that, except for income received from their primary employers, no financial support or compensation has been received from any individual or corporate entity over the past three years for research or professional service and there are no personal financial holdings that could be perceived as constituting a potential conflict of interest.

\section{REFERENCES}

Adams KH, Pinborg LH, Svarer C, Hasselbalch SG, Holm S, Haugbol $S$ et al (2004). A database of [(18)F]-altanserin binding to 5-HT(2A) receptors in normal volunteers: normative data and relationship to physiological and demographic variables. Neuroimage 21: 1105-1113.

Akiskal HS, Benazzi F (2006). The DSM-IV and ICD-10 categories of recurrent [major] depressive and bipolar II disorders: evidence that they lie on a dimensional spectrum. J Affect Disord 92: 45-54.

Attar-Levy D, Martinot JL, Blin J, Dao-Castellana MH, Crouzel C, Mazoyer B et al (1999). The cortical serotonin2 receptors studied with positron-emission tomography and [18F]-setoperone during depressive illness and antidepressant treatment with clomipramine. Biol Psychiatry 45: 180-186.

Barr CS, Newman TK, Schwandt M, Shannon C, Dvoskin RL, Lindell SG et al (2004a). Sexual dichotomy of an interaction between early adversity and the serotonin transporter gene promoter variant in rhesus macaques. Proc Natl Acad Sci USA 101: 12358-12363.

Barr CS, Newman TK, Shannon C, Parker C, Dvoskin RL, Becker ML et al (2004b). Rearing condition and rh5-HTTLPR interact to influence limbic-hypothalamic-pituitary-adrenal axis response to stress in infant macaques. Biol Psychiatry 55: 733-738.

Berton O, Aguerre S, Sarrieau A, Mormede P, Chaouloff F (1998). Differential effects of social stress on central serotonergic activity and emotional reactivity in Lewis and spontaneously hypertensive rats. Neuroscience 82: 147-159.

Bhagwagar Z, Hinz R, Taylor M, Fancy S, Cowen P, Grasby P (2006). Increased 5-HT(2A) receptor binding in euthymic, medication-free patients recovered from depression: a positron emission study with [(11)C]MDL 100,907. Am J Psychiatry 163: 1580-1587.

Biver F, Wikler D, Lotstra F, Damhaut P, Goldman S, Mendlewicz J (1997). Serotonin 5-HT2 receptor imaging in major depression: focal changes in orbito-insular cortex. $\mathrm{Br} J$ Psychiatry 171: 444-448.

Brummett BH, Boyle SH, Siegler IC, Kuhn CM, Ashley-Koch A, Jonassaint CR et al (2007). Effects of Environmental Stress and Gender on Associations among symptoms of depression and the serotonin transporter gene linked polymorphic region (5-HTTLPR). Behav Genet 38: 34-43.

Cahir M, Ardis T, Reynolds GP, Cooper SJ (2007). Acute and chronic tryptophan depletion differentially regulate central 5-HT1A and 5-HT 2A receptor binding in the rat. Psychopharmacology (Berl) 190: 497-506.

Caspi A, Sugden K, Moffitt TE, Taylor A, Craig IW, Harrington H et al (2003). Influence of life stress on depression: moderation by a polymorphism in the 5-HTT gene. Science 301: 386-389.

Christensen MV, Kyvik KO, Kessing LV (2007). Subclinical psychopathology and socio-economic status in unaffected twins discordant for affective disorder. J Psychiatr Res 41: 229-238.

Dwivedi Y, Mondal AC, Payappagoudar GV, Rizavi HS (2005). Differential regulation of serotonin (5HT)2A receptor mRNA and protein levels after single and repeated stress in rat brain: role in learned helplessness behavior. Neuropharmacology 48: 204-214.

Erritzoe D, Frokjaer VG, Haugbol S, Marner L, Svarer C, Holst K et al (2009). Brain serotonin 2A receptor binding: relations to body mass index, tobacco and alcohol use. Neuroimage 46: 23-30.

Fanous A, Gardner CO, Prescott CA, Cancro R, Kendler KS (2002). Neuroticism, major depression and gender: a population-based twin study. Psychol Med 32: 719-728.

Fanous AH, Neale MC, Aggen SH, Kendler KS (2007). A longitudinal study of personality and major depression in a population-based sample of male twins. Psychol Med 37: 1163-1172.

Frokjaer VG, Mortensen EL, Nielsen FA, Haugbol S, Pinborg LH, Adams $\mathrm{KH}$ et al (2008). Frontolimbic serotonin 2A receptor binding in healthy subjects is associated with personality risk factors for affective disorder. Biol Psychiatry 63: 569-576.

Gaspar P, Cases O, Maroteaux L (2003). The developmental role of serotonin: news from mouse molecular genetics. Nat Rev Neurosci 4: 1002-1012.

Gotlib IH, Joormann J, Minor KL, Hallmayer J (2008). HPA axis reactivity: a mechanism underlying the associations among 5-HTTLPR, stress, and depression. Biol Psychiatry 63: 847-851.

Gunther L, Liebscher S, Jahkel M, Oehler J (2008). Effects of chronic citalopram treatment on 5-HT1A and 5-HT2A receptors in group- and isolation-housed mice. Eur J Pharmacol 593: 49-61.

Hasin DS, Goodwin RD, Stinson FS, Grant BF (2005). Epidemiology of major depressive disorder: results from the national epidemiologic survey on alcoholism and related conditions. Arch Gen Psychiatry 62: 1097-1106.

Heal DJ, Philpot J, Molyneux SG, Metz A (1985). Intracerebroventricular administration of 5,7-dihydroxytryptamine to mice increases both head-twitch response and the number of cortical 5-HT2 receptors. Neuropharmacology 24: 1201-1205.

Jacobs N, Kenis G, Peeters F, Derom C, Vlietinck R, van Os J (2006). Stress-related negative affectivity and genetically altered serotonin transporter function: evidence of synergism in shaping risk of depression. Arch Gen Psychiatry 63: 989-996.

Kajantie E (2006). Fetal origins of stress-related adult disease. Ann NY Acad Sci 1083: 11-27.

Kendler KS, Gatz M, Gardner CO, Pedersen NL (2006a). A Swedish national twin study of lifetime major depression. Am J Psychiatry 163: 109-114.

Kendler KS, Gatz M, Gardner CO, Pedersen NL (2006b). Personality and major depression: a Swedish longitudinal, population-based twin study. Arch Gen Psychiatry 63: 1113-1120.

Kendler KS, Kessler RC, Walters EE, MacLean C, Neale MC, Heath AC et al (1995). Stressful life events, genetic liability, and onset of an episode of major depression in women. Am J Psychiatry 152: $833-842$. 
Kendler KS, Neale MC, Kessler RC, Heath AC, Eaves LJ (1993a). A longitudinal twin study of personality and major depression in women. Arch Gen Psychiatry 50: 853-862.

Kendler KS, Neale MC, MacLean CJ, Heath AC, Eaves LJ, Kessler RC (1993b). Smoking and major depression. A causal analysis. Arch Gen Psychiatry 50: 36-43.

Kendler KS, Pedersen NL, Farahmand BY, Persson PG (1996). The treated incidence of psychotic and affective illness in twins compared with population expectation: a study in the Swedish Twin and Psychiatric Registries. Psychol Med 26: 1135-1144.

Kutcher S, Marton P (1991). Affective disorders in first-degree relatives of adolescent onset bipolars, unipolars, and normal controls. J Am Acad Child Adolesc Psychiatry 30: 75-78.

Levinson DF (2006). The genetics of depression: a review. Biol Psychiatry 60: 84-92.

Mannie ZN, Harmer CJ, Cowen PJ (2007). Increased waking salivary cortisol levels in young people at familial risk of depression. Am J Psychiatry 164: 617-621.

Messa C, Colombo C, Moresco RM, Gobbo C, Galli L, Lucignani G et al (2003). 5-HT(2A) receptor binding is reduced in drug-naive and unchanged in SSRI-responder depressed patients compared to healthy controls: a PET study. Psychopharmacology (Berl) 167: 72-78.

Meyer JH, Kapur S, Eisfeld B, Brown GM, Houle S, DaSilva J et al (2001). The effect of paroxetine on 5-HT(2A) receptors in depression: an [(18)F]setoperone PET imaging study. Am J Psychiatry 158: 78-85.

Meyer JH, McMain S, Kennedy SH, Korman L, Brown GM, DaSilva JN et al (2003). Dysfunctional attitudes and 5-HT2 receptors during depression and self-harm. Am J Psychiatry 160: 90-99.

Modell S, Lauer CJ, Schreiber W, Huber J, Krieg JC, Holsboer F (1998). Hormonal response pattern in the combined DEX-CRH test is stable over time in subjects at high familial risk for affective disorders. Neuropsychopharmacology 18: 253-262.

Moffitt TE, Caspi A, Rutter M (2005). Strategy for investigating interactions between measured genes and measured environments. Arch Gen Psychiatry 62: 473-481.

Mormede P, Courvoisier H, Ramos A, Marissal-Arvy N, Ousova O, Desautes C et al (2002). Molecular genetic approaches to investigate individual variations in behavioral and neuroendocrine stress responses. Psychoneuroendocrinology 27: 563-583.

Müller-Gärtner HW, Links JM, Prince JL, Bryan RN, McVeigh E, Leal JP et al (1992). Measurement of radiotracer concentration in brain gray matter using positron emission tomography: MRIbased correction for partial volume effects. J Cereb Blood Flow Metab 12: 571-583.
Pinborg LH, Adams KH, Svarer C, Holm S, Hasselbalch SG, Haugbol S et al (2003). Quantification of 5-HT2A receptors in the human brain using $[18 \mathrm{~F}]$ altanserin-PET and the bolus/ infusion approach. J Cereb Blood Flow Metab 23: 985-996.

Pini S, de Queiroz V, Pagnin D, Pezawas L, Angst J, Cassano GB et al (2005). Prevalence and burden of bipolar disorders in European countries. Eur Neuropsychopharmacol 15: 425-434.

Portella MJ, Harmer CJ, Flint J, Cowen P, Goodwin GM (2005). Enhanced early morning salivary cortisol in neuroticism. Am J Psychiatry 162: 807-809.

Quarantelli M, Berkouk K, Prinster A, Landeau B, Svarer C, Balkay L et al (2004). Integrated software for the analysis of brain PET/ SPECT studies with partial-volume-effect correction. J Nucl Med 45: 192-201.

Skovdahl-Hansen H, Mortensen EL, Scioetz HK (2004). Dokumentation for den danske udgave af NEO PI-R og NEO PI-R Kort Version. Dansk psykologisk forlag: Copenhagen, Denmark.

Stockmeier CA (2003). Involvement of serotonin in depression: evidence from postmortem and imaging studies of serotonin receptors and the serotonin transporter. J Psychiatr Res 37: 357-373.

Svarer C, Madsen K, Hasselbalch SG, Pinborg LH, Haugbol S, Frokjaer VG et al (2005). MR-based automatic delineation of volumes of interest in human brain PET images using probability maps. Neuroimage 24: 969-979.

Talge NM, Neal C, Glover V (2007). Antenatal maternal stress and long-term effects on child neurodevelopment: how and why? J Child Psychol Psychiatry 48: 245-261.

Trajkovska V, Kirkegaard L, Krey G, Marcussen AB, Thomsen MS, Chourbaji $S$ et al (2009). Activation of glucocorticoid receptors increases 5-HT2A receptor levels. Exp Neurol 218: 83-91.

Uher R, McGuffin P (2008). The moderation by the serotonin transporter gene of environmental adversity in the aetiology of mental illness: review and methodological analysis. Mol Psychiatry 13: 131-146.

Vinberg M, Mortensen EL, Kyvik KO, Kessing LV (2007). Personality traits in unaffected twins discordant for affective disorder. Acta Psychiatr Scand 115: 442-450.

Woods RP, Cherry SR, Mazziotta JC (1992). Rapid automated algorithm for aligning and reslicing PET images. J Comput Assist Tomogr 16: 620-633.

Yatham LN, Liddle PF, Shiah IS, Scarrow G, Lam RW, Adam MJ et al (2000). Brain serotonin2 receptors in major depression: a positron emission tomography study. Arch Gen Psychiatry 57: $850-858$ 